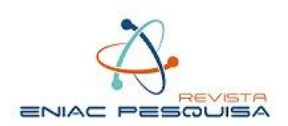

\title{
Relatos Integrados das Indústrias Siderúrgicas: Análise Comparativa das Empresas CSN - Cia. Siderúrgica Nacional e Gerdau
}

Integrated Reports of the Steel Industries: Comparative Analysis of CSN Companies - Cia. Siderúrgica Nacional and Gerdau

Recebimento: 15/02/2021 - Aceite: 24/03/2021 - Publicação: 1/09/2021

Processo de Avaliação: Double Blind Review

Thaina Silva da Rosa

Graduada em Tecnologia em Gestão Financeira

Faculdade de Tecnologia Prefeito Hirant Sanazar - Osasco

thainaroosa@hotmail.com

https://orcid.org/0000-0002-5876-8659

Gislaine Fernandes dos Santos

Graduada em Tecnologia em Gestão Financeira

Faculdade de Tecnologia Prefeito Hirant Sanazar - Osasco

gislaine.fersan@gmail.com

https://orcid.org/0000-0001-8870-2573

\section{Fernando de Almeida Santos}

Professor do Mestrado Profissional em Ciências Contábeis, Controladoria e Finanças da PUCSP e Pesquisador do NUPE - ENIAC

fernando@fernandoasantos.com.br

https://orcid.org/0000-0002-1716-2802

Roberta Cristina da Silva

Mestre pelo Mestrado em Ciências Contábeis e Atuariais pela PUC-SP

robertasilvact@gmail.com

https://orcid.org/0000-0001-8827-0977

\section{RESUMO}

Este artigo aborda informações sobre a formação do Relato Integrado, a discussão socioambiental e os impactos ambientais de Indústrias Siderúrgicas. O setor siderúrgico tem grande importância para as demais indústrias de construção, tendo um faturamento de $\mathrm{R} \$ 98,5$ bilhões de acordo com o Anuário do Instituto Aço Brasil 2020, pela sua grandeza a divulgação de informações socioambientais como apresentado em um Relato Integrado, auxilia na criação de valor a longo prazo da empresa e na prestação de contas para com a sociedade. O estudo tem como objetivo comparar o relato das empresas e verificar a forma de apresentação das informações. Foi realizada pesquisa comparativa e as empresas foram delimitadas pelas indústrias siderúrgicas que apresentam o Relato Integrado, sendo elas CSN 


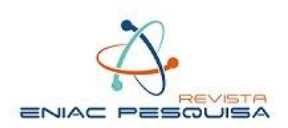

- Cia Siderúrgica Nacional e Gerdau. O estudo conseguiu identificar que a empresa CSN tem maior riqueza de detalhes e os relatos estão evoluindo de maneira que ficam mais completos e transparentes. O tema abordado pode auxiliar as empresas a desenvolverem instrumentos com maior comparabilidade interna e externa e auxiliar na tomada decisão, além de possibilitar reflexões sobre indicadores sociais, ambientais e econômicos.

Palavras-chave: relato integrado, sustentabilidade, setor siderúrgico

\section{ABSTRACT}

This article addresses information on the formation of the Integrated Report, a socioenvironmental discussion and the environmental impacts of Steel Industries. The steel sector is of great importance for the other construction industries, having a turnover of $R \$ 98.5$ billion according to the Yearbook of the Brazil Steel Institute 2020, due to its greatness the dissemination of social and environmental information as presented in an Integrated Report, helps in creating long-term value for the company and accountability to society. The study aims to compare the companies' reports and verify the presentation of the information. Comparative research was carried out and the companies were delimited by the steel industries that present the Integrated Report, being CSN - Cia Siderúrgica Nacional and Gerdau. The study was able to identify that the CSN company has a greater wealth of details and the reports are evolving in a way that they are complete and transparent. The topic addressed can help companies to develop instruments with greater internal and external comparability and assist in decision making, in addition to enabling reflections on social, environmental and economic indicators.

Key-Words: integrated reporting, sustainability, steel sector

\section{INTRODUÇÃO}

Este artigo irá comparar os relatos integrados das empresas CSN - Cia Siderúrgica Nacional e Gerdau nos indicadores apresentados. Segundo o IIRC (2013), o Relato Integrado virando um padrão para relatos corporativos, tem uma visão a longo prazo de um mundo enraizado com as práticas comerciais dos setores públicos e privados. Seu ciclo de pensamento trata-se de uma alocação eficiente e produtiva de capital, funcionando como força para conferir a estabilidade financeira e sustentável. 
O Relato Integrado abrange seis tipos de capital, sendo eles: capital financeiro, capital manufaturado, capital intelectual, capital humano, capital social e de relacionamento e capital natural.

De acordo com o anuário do Instituto Aço Brasil (2020), o setor siderúrgico faturou cerca de 98.2 bilhões de reais e produziu 32.6 milhões de toneladas de aço bruto em 2019. Por ser um setor grande que está em constante crescimento, há impactos negativos no meio ambiente, como por exemplo o uso de carvão vegetal e o uso de muita energia térmica, onde os processos realizados pela indústria poluem a atmosfera com óxidos de enxofre (SOx), monóxido de carbono (CO), entre outros gases de efeito estufa. Pela grandeza do setor e sua área de atuação, é possível verificar a importância da responsabilidade social, ambiental e econômica.

Portanto, este artigo tem como objetivo comparar o Relato Integrado das empresas do segmento siderúrgico: CSN - Cia Siderúrgica Nacional e Gerdau no ano de 2019.

\section{IMPORTÂNCIA DA DISCUSSÃO SOCIAL, AMBIENTAL E ECONÔMICA}

A ECO 92 foi uma conferência realizada no Rio de Janeiro em 1992, que contou com mais de 179 países. Na data, foram aprovadas as convenções sobre biodiversidade e sobre mudanças climáticas, um importante acontecimento foram as assinaturas realizadas para a Agenda 21, que trata de metas para melhorar as condições ambientais do planeta.

A Agenda 21 (global, 1992) aborda 4 ramos:

- Dimensões sociais e econômicas: trata-se do combate à pobreza, colaboração internacional para o desenvolvimento sustentável, mudança dos padrões de consumo, proteção e promoção das condições da saúde humana, integração entre o meio ambiente e desenvolvimento na tomada de decisões, desenvolvimento sustentável dos assentamentos humanos;

- Conservação e gestão dos recursos para o desenvolvimento: proteção da atmosfera, planejamento e gerenciamento dos recursos terrestres, combate ao desflorestamento, luta contra a desertificação e a seca, desenvolvimento sustentável das montanhas, desenvolvimento rural e agrícola sustentável, conservação da diversidade biológica, manejo ambientalmente saudável da biotecnologia, manejo ambientalmente saudável dos resíduos sólidos, e etc;

- Fortalecimento do papel dos grupos principais: ação mundial pela mulher, com vistas a um desenvolvimento sustentável equitativo, fortalecimento do papel dos 


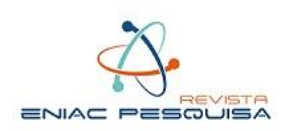

agricultores, fortalecimento do papel das organizações não-governamentais: parceiros para um desenvolvimento sustentável, reconhecimento e fortalecimento do papel das populações indígenas e suas comunidades etc.;

- Meios de implementação: recursos e mecanismos de financiamento, a ciência para o desenvolvimento sustentável, arranjos institucionais internacionais, informação para a tomada de decisões.

A ONU tem como objetivo acabar com a pobreza, proteger o meio ambiente e o clima e garantir que as pessoas possam ter paz e prosperidade. Há um projeto para o desenvolvimento Sustentável no Brasil, algumas de suas metas e objetivos são:

- Erradicação da pobreza: acabar com a pobreza em todas as suas formas, em todos os lugares;

- Saúde e Bem-Estar: assegurar uma vida saudável e promover o bem-estar para todas e todos, em todas as idades;

- Consumo e produção responsáveis: assegurar padrões de produção e de consumo sustentáveis;

- Ação contra a mudança global do clima: tomar medidas urgentes para combater a mudança climática e seus impactos;

- Vida na água: conservação e uso sustentável dos oceanos, dos mares e dos recursos marinhos para o desenvolvimento sustentável;

- Vida terrestre: Proteger, recuperar e promover o uso sustentável dos ecossistemas terrestres, gerir de forma sustentável as florestas, combater a desertificação, deter e reverter a degradação da terra e deter a perda de biodiversidade;

- Indústria, inovação e infraestrutura: construir infraestruturas resilientes, promover a industrialização inclusiva e sustentável e fomentar a inovação;

- Energia limpa e acessível: Assegurar o acesso confiável, sustentável, moderno e a preço acessível à energia para todas e todos.

Há diversos projetos, instituições e ONGs que tem como objetivo a preservação do meio ambiente e a proteção a população humana, para que todos tenham uma vida boa e próspera, com saúde e um planeta sustentável. Nos dias de hoje já há uma grande quantidade de impactos ambientais, porém se as discussões sobre o tema continuarem e conscientizarem a população, principalmente os empresários e as indústrias, é possível diminuir esses impactos e colaborar com um planeta sustentável, onde seja possível proteger florestas, mares, lagos, rios, montanhas e a atmosfera e futuramente garantir um planeta bom para se habitar. 


\section{RELATO INTEGRADO}

Segundo o IIRC (2013), o Relato Integrado virando um padrão para relatos corporativos, tem uma visão a longo prazo de um mundo enraizado com as práticas comerciais dos setores públicos e privados. Seu ciclo de pensamento trata-se de uma alocação eficiente e produtiva de capital, funcionando como força para conferir a estabilidade financeira e sustentável.

Conforme Balardim (2017) os objetivos do Relato Integrado são: aprimorar a qualidade das informações para os fornecedores de capital financeiro, permitindo uma alocação eficiente e produtiva do capital, impulsionar uma abordagem coesa e eficiente para os relatórios corporativos, onde pode melhorar a capacidade de uma empresa para ganhar valor ao longo do tempo, aperfeiçoar a prestação de contas e a gestão e promover suas interdependências, suporte integrando pensamentos, colaborar na tomada de decisão e ações para ganho de valor ao longo do tempo.

O Relato Integrado é uma inovação no mundo corporativo, visto que identifica aspectos não financeiros que podem contribuir na criação de valor da empresa (Silva, Santos e Santos, 2019).

\section{DESCRIÇÃO DOS CAPITAIS}

Segundo IIRC (2013), os capitais para desenvolvimento do Relato Integrado são:

- Capital Financeiro: é um conjunto de recursos disponibilizados para utilização na produção de bens ou prestação de serviços na organização, são obtidos por meio de financiamentos, como dívidas, ações, subvenções, ou por meio dos investimentos.

Conforme Gittmann (1996) investidores que cedem seu excesso de caixa para empréstimos, ou mesmo para adquirir direitos legais sobre outros agentes e assim obter ganhos futuros, trata-se de um circuito de investimento tendo como base créditos e ativos (em papel) para que haja produção de ativos que criam rendas, este processo pode ser definido como capital financeiro. De um modo geral refere-se a gastar dinheiro para obter mais dinheiro no futuro.

- Capital Manufaturado: são os objetos físicos (também disponibilizados para utilização na produção), esses objetos são os prédios, equipamentos e infraestrutura. Muitas vezes esse capital é gerado por outras organizações, porém é incluído nos ativos fabricados pela organização relatora. 
Conforme a Comissão Nacional de Classificação, a siderurgia é um grupo da divisão metalúrgica que compõem a seção de indústrias de transformação, a mesma é responsável pela produção de semiacabados de aço, laminados planos de aço, laminados longos de aço e relaminados, trefilados e perfilados de aço.

- Capital Intelectual: trata-se dos intangíveis, sendo a propriedade intelectual que se refere a patentes, direitos autorais, software, direitos e licenças e o capital organizacional que se refere ao conhecimento tácito, sistemas, procedimentos e protocolos.

Porém, conforme Lynn, 2000 (in Vaz et al., 2014), o Capital Intelectual pode ser divido em três partes, são eles: Capital Humano que abrange as competências individuais e coletivas da empresa, é um recurso não permanente, porém integram habilidades técnicas e emocionais que colaboram com o aumento do potencial produtivo e de inovação, um capital humano bem desenvolvido colabora com a eficácia e a eficiência da empresa. Capital Relacional: trata-se dos intangíveis, sua estrutura externa, relacionamento com clientes, imagem da empresa e fornecedores, de acordo com a autora, a fidelidade desses clientes e fornecedores impactam na busca por novos clientes, onde é possível ganhar credibilidade para novos e manutenção dos antigos. Capital Estrutural: este capital trabalha junto com o capital humano, porém é permanente na empresa, o mesmo trata de processos referente ao funcionamento da empresa onde é composto pelos capitais de inovação, relações e processos, pode-se considerar que há o ganho de um auxílio para geração de valor na empresa.

- Capital Humano: se refere as competências, habilidades e experiencias das pessoas, onde inclui-se alinhamento e apoio à estrutura de governança, gerenciamento de riscos e valores éticos, capacidade no entendimento, desenvolvimento e implantação da estratégica na organização, lealdade e motivação para aperfeiçoamento dos processos, bens e serviços, englobando a capacidade de liderança, gerenciamento e colaboração.

Ou seja, o capital humano são os indivíduos, em uma empresa, são os funcionários, onde estes podem desenvolver habilidades que ajudam no processo de produção, porém as empresas devem focar neste capital para a evolução do seu quadro de funcionário, sendo considerada uma empresa de carreira ou não, mas as oportunidades que podem existir, podem estimular os funcionários.

- Capital Social e de Relacionamento: tendo o foco de compartilhar informações para aperfeiçoar o bem-estar individual e coletivo, abrange os padrões compartilhados, 


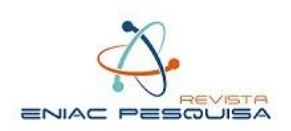

valores e comportamentos comuns, confiança e compromisso que a organização deve desenvolver e procurar construir com as partes interessadas externas, intangíveis que estão associados a marca e a reputação desenvolvida e licença social para que a organização possa operar.

O capital social e de relacionamento deve ser aprimorado visto poder melhorar a convivência no ambiente, tornar os indivíduos em uma equipe com propósitos em comum.

- Capital Natural: trata-se dos recursos ambientais renováveis e não renováveis, seus processos ambientais que além de fornecer bens e serviços, apoiam a prosperidade passada, presente e futura da organização. Esses recursos são: água, terra, minerais, florestas, biodiversidade e a qualidade do ecossistema.

Para O'Connor (1999) qualquer elemento ou sistema do mundo físico que fornecem materiais, energia ou serviços de valor à sociedade é considerado capital natural.

$\mathrm{Ou}$ seja, o capital natural são materiais naturais que podem ser convertidos em produtos úteis.

\section{SETOR SIDERÚRGICO}

Conforme Carvalho et. al (2015), a indústria siderúrgica é responsável pelo fornecimento de materiais à outras indústrias e principalmente para a construção civil, operando em diversas fases do minério de ferro primário, participa dos processos para produção de ferro-gusa e bobinas laminadas que são utilizadas na indústria automotiva. Para o setor de habitação e infraestrutura são usados os laminados longos, como por exemplo o vergalhão. Um produto muito importante também são os tubos de aço. No Brasil, a maior produção é de aço carbono comum, vale ressaltar que os mesmos produtos que são fabricados com aço carbono podem ser fabricados por aço especial ou ligados.

De acordo com o anuário do Instituto Aço Brasil (2020), o setor siderúrgico faturou cerca de 98.2 bilhões de reais e produziu 32.6 milhões de toneladas de aço bruto, sendo 390 t/homem/ano em 2019, mundialmente a produção é de 1.875,0 milhões de toneladas. O Brasil está em $9^{\circ}$ no ranking mundial e conta com 32 usinas. Na América Latina a produção é de 60,6 milhões de toneladas, sendo assim o Brasil representa 53,8\% desta produção.

Conforme Matos (2010), a indústria metalmecânica, que é composta pelas metalúrgicas, siderúrgicas e responsáveis pela produção de equipamentos mecânicos, polui o meio ambiente por meio da extração de metais de seus minérios, obtenção de ligas e os acabamentos mecânicos. Os principais poluentes do ar são: As (arsênio), Cd (cádmio), Cr 


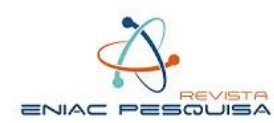

(crômio), $\mathrm{Cu}$ (cobre), $\mathrm{Mn}$ (manganês), $\mathrm{Ni}$ (níquel), $\mathrm{Pb}$ (chumbo), Sb (antimômio), Ti (titânio)

e Zn (zinco). O que mais polui as águas são: íons metálicos, resíduos ácidos e carbono orgânico volátil (COV). Enquanto os poluentes do solo são: solventes, metais presentes nos resíduos, aerossóis de fundição, resíduos ácidos e processos pirometalúrgicos. Devido esses impactos ambientais, é possível verificar a importância da responsabilidade socioambiental que uma indústria siderúrgica deve ter.

\section{PESQUISAS REALIZADAS SOBRE A TEMÁTICA}

Na tabela 1 apresenta-se pesquisas realizadas recentemente sobre a temática deste artigo:

\section{Tabela 1}

Estudos recentes

\begin{tabular}{|c|c|c|c|}
\hline Trabalhos & Autores & Objetivos & Ano \\
\hline $\begin{array}{l}\text { Modelo de implementação de } \\
\text { um sistema integrado de gestão } \\
\text { da qualidade e ambiente em } \\
\text { uma empresa de aço }\end{array}$ & $\begin{array}{l}\text { Ibañez, Rios e } \\
\text { Montoya. }\end{array}$ & $\begin{array}{l}\text { Apresentação de um modelo de gestão } \\
\text { eficaz, onde se obtém otimização dos } \\
\text { processos internos e cumprimento dos } \\
\text { requisitos das normas ISO 9001: } 2015 \text { e ISO } \\
\text { 14001: } 2015 \text {. }\end{array}$ & 2018 \\
\hline $\begin{array}{l}\text { Por trás } \quad \text { do discurso } \\
\text { socialmente } \\
\text { siderurgia mineira }\end{array}$ & $\begin{array}{l}\text { Andrade, } \\
\text { Gosling } \\
\text { Xavier }\end{array}$ & $\begin{array}{l}\text { Análise do balanço social das empresas } \\
\text { selecionadas e sua real motivação atrás dos } \\
\text { discursos socioambientais. }\end{array}$ & 2010 \\
\hline $\begin{array}{l}\text { Impactos socioambientais na } \\
\text { Amazônia Oriental um olhar a } \\
\text { partir da atividade siderúrgica } \\
\text { na comunidade Piquiá de Baixo } \\
\text { - Açailândia (MA) }\end{array}$ & Silva & $\begin{array}{l}\text { Análise do processo de implantação de } \\
\text { siderúrgicas na cidade de Açailandia - MA e } \\
\text { seus impactos ambientais, sociais, culturais e } \\
\text { territoriais. }\end{array}$ & 2019 \\
\hline $\begin{array}{l}\text { Terceirização de mão de obra } \\
\text { na siderurgia argentina: } \\
\text { empresas de ex-trabalhadores } \\
\text { em Acindar Villa Constitución } \\
\text { e Siderar Ensenada }\end{array}$ & Sponda e Strada & $\begin{array}{l}\text { Análise comparativa referente a expansão da } \\
\text { terceirização baseada na subcontratação de } \\
\text { empresas de ex-trabalhadores de indústrias } \\
\text { siderúrgicas na Argentina. }\end{array}$ & 2019 \\
\hline $\begin{array}{l}\text { Relato integrado e a } \\
\text { convergência com relatórios de } \\
\text { sustentabilidade: Um estudo em } \\
\text { empresas brasileiras }\end{array}$ & $\begin{array}{l}\text { Peixoto } \\
\text { Martins }\end{array}$ & $\begin{array}{l}\text { Comparação do Relato Integrado da empresa } \\
\text { Votorantim Industrial nos anos de } 2012 \text { e } \\
2013 \text { para verificação do nível de divulgação } \\
\text { de informações no Relato Integrado. }\end{array}$ & 2015 \\
\hline $\begin{array}{l}\text { A evolução dos relatórios de } \\
\text { sustentabilidade e a necessidade } \\
\text { da obrigatoriedade de sua } \\
\text { asseguração por terceiros }\end{array}$ & $\begin{array}{l}\text { Nagano, Kassai, } \\
\text { Kussaba e } \\
\text { Carvalho }\end{array}$ & $\begin{array}{l}\text { Discussão da necessidade de tornar } \\
\text { obrigatório avaliar as informações } \\
\text { apresentadas no Relato Integrado como } \\
\text { ocorre com os relatórios financeiros que } \\
\text { passam por auditoria antes de serem } \\
\text { publicados. }\end{array}$ & 2014 \\
\hline $\begin{array}{l}\text { A atuação do Relato Integrado } \\
\text { nas empresas brasileiras: Um } \\
\text { estudo comparativo sobre a } \\
\text { forma de divulgação do RI } \\
\text { entre os dois maiores bancos } \\
\text { privados nacionais }\end{array}$ & $\begin{array}{l}\text { Silva, Santos e } \\
\text { Santos }\end{array}$ & $\begin{array}{l}\text { Análise da divulgação de informações do } \\
\text { Relato Integrado, comparando as diferenças } \\
\text { e semelhanças nos aspectos de capital, } \\
\text { criação de valor e plano estratégico dos dois } \\
\text { grandes bancos privados: Itaú Unibanco e } \\
\text { Bradesco. }\end{array}$ & 2019 \\
\hline
\end{tabular}

Fonte: Elaborado pelos autores. 2021. 


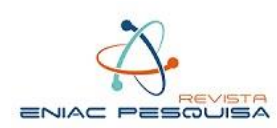

As pesquisas apresentadas no quadro acima, abrangem os impactos ambientais, culturais e sociais da Indústria Siderúrgica, além de demonstrar a importância e o avanço do Relato Integrado, mesmo não sendo um relatório obrigatório tem sua importância e com essas pesquisas sobre assunto, o tema fica cada vez mais conhecido, sendo discutido e apresentado como opção para empresas de diversos setores. Além disso, é possível verificar os motivos por trás do discurso socioambiental.

Sendo uma importante discussão para empresas que causam impacto no meio ambiente, visto que há impactos negativos, o Relato Integrado pode ser realizado por empresas de outros segmentos também, e essa valorização contribui na divulgação do Relato Integrado, para que mais empresas divulguem suas atitudes socioambientais.

\section{METODOLOGIA}

A metodologia utilizada neste artigo trata-se de uma análise qualitativa comparativa, com o objetivo de analisar os capitais dos relatos integrados das empresas CSN - Cia Siderúrgica Nacional e Gerdau no ano de 2019.

Conforme a planilha disponibilizada pela B3 no Relate ou Explique, as empresas no segmento siderúrgico são: CIA Ferro Ligas da Bahia - Ferbasa, CSN - Cia Siderúrgica Nacional, USIMINAS e Gerdau, dentre elas, apenas as empresas CSN - Cia Siderúrgica Nacional e Gerdau apresentaram o Relato Integrado, portanto a pesquisa foi realizada em cima dos relatos do ano de 2019 para descrição e comparação das duas empresas.

A pesquisa realizada para a argumentação da importância da discussão sustentável, ambiental e econômica, foi baseada na Agenda 21, assinada na conferência da ECO-92 e do site da ONU, onde especifica projetos e objetivos sustentáveis para o Brasil. Além de acrescentar os impactos que as indústrias siderúrgicas causam no meio ambiente.

Os capitais obrigatórios para o relato integrado foram extraídos das normas de Relato Integrado, conforme IIRC (2013), sendo estes: capital financeiro, capital manufaturado, capital intelectual, capital humano, capital social e de relacionamento e capital humano. Seus principais focos e objetivos abrangem diversos autores que foram detalhados em cada capital. A explicação da produtividade de materiais da indústria siderúrgica e a grandeza do setor, produção mundial e produção nacional, foram analisados por artigos do setor e pelo Anuário do Instituto Aço Brasil (2020).

O quadro comparativo foi desenvolvido de acordo com as informações apresentadas nos relatos das empresas. 


\section{RESULTADOS E DISCUSSÕES}

Nos resultados apresenta-se uma comparação entre as empresas CSN - Cia Siderúrgica Nacional e Gerdau de todos os capitais do relatório de sustentabilidade.

No capital intelectual, conforma a Tabela 2, é notável a facilidade de busca de informações no relato da CSN, pois o relato da Gerdau não separa os indicadores em capitais e a busca deve ser feita como um todo, dificultando a pesquisa das informações. Para além deste detalhe, ambos os relatos informam bem sobre seus projetos e investimentos.

\section{Tabela 2}

Indicadores relacionados ao capital intelectual

\begin{tabular}{|c|c|c|c|}
\hline Indicadores & $\begin{array}{c}\text { CSN - Cia Siderúrgica } \\
\text { Nacional }\end{array}$ & Gerdau & Comentário \\
\hline $\begin{array}{l}\text { Investimento } \\
\text { em startups }\end{array}$ & $\begin{array}{l}\text { A empresa divulga em forma } \\
\text { de texto o investimento em } \\
\text { startups. }\end{array}$ & $\begin{array}{l}\text { A empresa divulga em } \\
\text { forma de texto o } \\
\text { investimento em startups. }\end{array}$ & $\begin{array}{l}\text { Neste indicador as empresas } \\
\text { divulgam seus investimentos } \\
\text { em startups e tecnologia. }\end{array}$ \\
\hline $\begin{array}{l}\text { Investimento } \\
\text { em estrutura }\end{array}$ & $\begin{array}{l}\text { A empresa divulga em forma } \\
\text { de texto informações sobre } \\
\text { seus investimentos em } \\
\text { estrutura laboratorial para } \\
\text { pesquisas e desenvolvimento. }\end{array}$ & $\begin{array}{l}\text { A empresa divulga em } \\
\text { forma de texto seus } \\
\text { investimentos em } \\
\text { pesquisa e tecnologia. }\end{array}$ & $\begin{array}{l}\text { Neste indicador são divulgadas } \\
\text { informações sobre } \\
\text { investimentos em pesquisas e } \\
\text { suas estruturas. }\end{array}$ \\
\hline $\begin{array}{l}\text { Principais } \\
\text { impactos para a } \\
\text { sociedade }\end{array}$ & $\begin{array}{l}\text { A empresa divulga os projetos } \\
\text { realizados e lista alguns de } \\
\text { seus impactos para a } \\
\text { sociedade. }\end{array}$ & $\begin{array}{l}\text { A empresa divulga por } \\
\text { meio de textos seus } \\
\text { projetos e impactos para } \\
\text { com a sociedade. }\end{array}$ & $\begin{array}{l}\text { Neste indicador são divulgadas } \\
\text { informações sobre os projetos } \\
\text { sociais e como a população é } \\
\text { impactada com a existência da } \\
\text { indústria próximo ao local dos } \\
\text { moradores. }\end{array}$ \\
\hline
\end{tabular}

Fonte: Elaborado pelos autores.

No capital apresentado na Tabela 3, é informada a produção de ambas as empresas, a diferença é que uma delas não informa a produção de determinado material, mas os demais têm um padrão. Vale ressaltar que o relato da Gerdau tem difícil manuseio devido à falta de padronização para a emissão deste. 


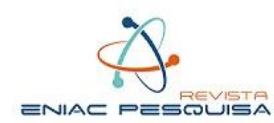

Tabela 3

Indicadores relacionados ao capital manufaturado

\begin{tabular}{|c|c|c|c|}
\hline Indicadores & $\begin{array}{c}\text { CSN - Cia Siderúrgica } \\
\text { Nacional }\end{array}$ & Gerdau & Comentário \\
\hline $\begin{array}{l}\text { Toneladas de aço } \\
\text { bruto }\end{array}$ & $\begin{array}{l}\text { A empresa divulga os } \\
\text { valores de produção em } \\
\text { forma de texto. }\end{array}$ & $\begin{array}{l}\text { A empresa divulga os } \\
\text { valores de produção em } \\
\text { forma de texto. }\end{array}$ & $\begin{array}{l}\text { Neste indicador, as empresas } \\
\text { informam a quantidade de aço } \\
\text { produzido e em qual local. }\end{array}$ \\
\hline $\begin{array}{l}\text { Toneladas de aço } \\
\text { plano }\end{array}$ & $\begin{array}{l}\text { A empresa divulga os } \\
\text { valores de produção em } \\
\text { forma de texto. }\end{array}$ & $\begin{array}{l}\text { Não informado a } \\
\text { quantidade de aço plano } \\
\text { produzido. }\end{array}$ & $\begin{array}{l}\text { Neste indicador uma das empresas } \\
\text { divulga sua produção. }\end{array}$ \\
\hline $\begin{array}{l}\text { Toneladas de aço } \\
\text { longo }\end{array}$ & $\begin{array}{l}\text { A empresa divulga os } \\
\text { valores de produção em } \\
\text { forma de texto. }\end{array}$ & $\begin{array}{l}\text { A empresa divulga os } \\
\text { valores de produção em } \\
\text { forma de texto. }\end{array}$ & $\begin{array}{l}\text { Neste indicador, as empresas } \\
\text { informam a quantidade de aço } \\
\text { produzido e em qual local. }\end{array}$ \\
\hline $\begin{array}{l}\text { Toneladas de aço, } \\
\text { especialmente } \\
\text { para o setor } \\
\text { automotivo }\end{array}$ & $\begin{array}{l}\text { A empresa divulga os } \\
\text { valores de produção em } \\
\text { forma de texto. }\end{array}$ & $\begin{array}{l}\text { Não informado } \text { a } \\
\text { quantidade de aço } \\
\text { produzido para o setor } \\
\text { automotivo. }\end{array}$ & $\begin{array}{l}\text { Neste indicador uma das empresas } \\
\text { divulga sua produção. }\end{array}$ \\
\hline $\begin{array}{l}\text { Toneladas de aço, } \\
\text { aço galvanizado } \\
\text { (incluindo o } \\
\text { Galvanew } ® \text { ) }\end{array}$ & $\begin{array}{l}\text { A empresa divulga os } \\
\text { valores de produção em } \\
\text { forma de texto. }\end{array}$ & $\begin{array}{l}\text { Não informado } \\
\text { quantidade de aço } \\
\text { galvanizado. }\end{array}$ & $\begin{array}{l}\text { Neste indicador uma das empresas } \\
\text { divulga sua produção. }\end{array}$ \\
\hline $\begin{array}{l}\text { Toneladas de } \\
\text { blanks, } \\
\text { chapas e rolos }\end{array}$ & $\begin{array}{l}\text { A empresa divulga os } \\
\text { valores de produção em } \\
\text { forma de texto. }\end{array}$ & $\begin{array}{l}\text { Não informado a } \\
\text { quantidade de blanks, } \\
\text { chapas e rolos. }\end{array}$ & $\begin{array}{l}\text { Neste indicador uma das empresas } \\
\text { divulga sua produção. }\end{array}$ \\
\hline $\begin{array}{l}\text { Toneladas de pré- } \\
\text { pintados }\end{array}$ & $\begin{array}{l}\text { A empresa divulga os } \\
\text { valores de produção em } \\
\text { forma de texto. }\end{array}$ & $\begin{array}{l}\text { Não informado a } \\
\text { quantidade de pré- } \\
\text { pintados. }\end{array}$ & $\begin{array}{l}\text { Neste indicador uma das empresas } \\
\text { divulga sua produção. }\end{array}$ \\
\hline $\begin{array}{l}\text { Toneladas } \\
\text { laminados } \\
\text { a quente }\end{array}$ & $\begin{array}{l}\text { A empresa divulga os } \\
\text { valores de produção em } \\
\text { forma de texto. }\end{array}$ & $\begin{array}{l}\text { A empresa divulga os } \\
\text { valores de produção em } \\
\text { forma de texto. }\end{array}$ & $\begin{array}{l}\text { A produção de aço laminado da } \\
\text { Gerdau é realizada na América } \\
\text { Latina, sendo na Argentina, no } \\
\text { Peru, no Uruguai e na Venezuela, } \\
\text { enquanto a CSN é nacional. }\end{array}$ \\
\hline
\end{tabular}

Fonte: Elaborado pelos autores.

\section{Tabela 4}

Indicadores relacionados ao capital financeiro

Indicadores

Receita Líquida

EBITDA

Lucro Líquido

Fluxo de caixa A empresa não informa seu

livre fluxo de caixa livre no relato integrado. passa algumas informações em alguns textos do relato. informações em uma tabela.

A empresa não informa seu lucro líquido no relato integrado.

\section{Gerdau}

A empresa divulga as informações em um gráfico.

A empresa divulga as A empresa divulga as

Fonte: Elaborado pelos autores. informações em um gráfico.

A empresa divulga as informações em um gráfico.

A empresa divulga as informações em um gráfico.

\section{Comentário}

Neste indicador as empresas divulgam as informações de forma parecida.

Neste indicador as empresas divulgam as informações de forma parecida.

Neste indicador as empresas não divulgam as informações de forma parecida ou padronizada.

Neste indicador as empresas não divulgam as informações de forma parecida ou padronizada. 
No capital humano, segundo a Tabela 4, é possível analisar a falta de padronização das empresas, pois enquanto uma apresenta informações como por exemplo o fluxo de caixa livre, a outra empresa não apresenta. Devido a Gerdau não ter um relato com a separação dos capitais, é necessário que se deduza onde estão as informações e buscá-la para verificar se a empresa informa.

\section{Tabela 5}

Indicadores relacionados ao capital humano

\begin{tabular}{|c|c|c|c|}
\hline Indicadores & $\begin{array}{c}\text { CSN - Cia Siderúrgica } \\
\text { Nacional } \\
\end{array}$ & Gerdau & Comentário \\
\hline $\begin{array}{l}\text { Colaborador } \\
\text { es próprios }\end{array}$ & $\begin{array}{l}\text { A empresa informa o número } \\
\text { total de colaboradores } \\
\text { próprios em um quadro. }\end{array}$ & $\begin{array}{l}\text { A empresa informa o } \\
\text { número total de } \\
\text { colaboradores próprios em } \\
\text { um gráfico, porém há } \\
\text { informações separadas } \\
\text { sobre sexo, gênero e etnia. }\end{array}$ & $\begin{array}{l}\text { Neste indicador as informações } \\
\text { são passadas de forma similar, } \\
\text { porém a Gerdau apresenta maior } \\
\text { detalhamento de seus } \\
\text { colaboradores. }\end{array}$ \\
\hline $\begin{array}{l}\text { Colaborador } \\
\text { es terceiros }\end{array}$ & $\begin{array}{l}\text { A empresa informa o número } \\
\text { total de colaboradores } \\
\text { terceirizados em um quadro. }\end{array}$ & $\begin{array}{l}\text { É informado o número de } \\
\text { colaboradores } \\
\text { terceirizados. }\end{array}$ & $\begin{array}{l}\text { Neste indicador é informado o } \\
\text { número total de terceiros de } \\
\text { maneira similar. }\end{array}$ \\
\hline $\begin{array}{l}\text { Iniciativas } \\
\text { de } \\
\text { diversidade }\end{array}$ & $\begin{array}{l}\text { A empresa informa suas ações } \\
\text { de diversidade em forma de } \\
\text { texto e separadamente para } \\
\text { cada causa. }\end{array}$ & $\begin{array}{l}\text { A empresa informa suas } \\
\text { ações de diversidade em } \\
\text { forma de texto e descreve } \\
\text { a jornada da diversidade e } \\
\text { inclusão. }\end{array}$ & $\begin{array}{l}\text { Neste indicador as empresas } \\
\text { apresentam informações sobre } \\
\text { suas ações de diversidade de } \\
\text { forma similar e passam as } \\
\text { porcentagens de funcionários. }\end{array}$ \\
\hline $\begin{array}{l}\text { Inclusão de } \\
\text { mulheres }\end{array}$ & $\begin{array}{l}\text { A empresa apresenta as } \\
\text { informações de inclusão de } \\
\text { mulheres em forma de texto e } \\
\text { apresenta a porcentagem e } \\
\text { crescimento das mulheres em } \\
\text { suas unidades de trabalho. }\end{array}$ & $\begin{array}{l}\text { A empresa apresenta as } \\
\text { informações da inclusão de } \\
\text { mulheres em forma de } \\
\text { texto, junto às informações } \\
\text { da inclusão de diversidade. }\end{array}$ & $\begin{array}{l}\text { Neste indicador as empresas } \\
\text { informam suas porcentagens de } \\
\text { mulheres, mas a CSN separa um } \\
\text { tópico para explicar essa } \\
\text { inclusão em suas unidades. }\end{array}$ \\
\hline $\begin{array}{l}\text { Treinamento } \\
\text { s realizados }\end{array}$ & $\begin{array}{l}\text { A empresa apresenta seus } \\
\text { treinamentos em forma de } \\
\text { texto e divulga a quantidade } \\
\text { de horas de treinamentos de } \\
\text { seus funcionários por setor. }\end{array}$ & $\begin{array}{l}\text { A empresa informa alguns } \\
\text { treinamentos em forma de } \\
\text { texto. }\end{array}$ & $\begin{array}{l}\text { Neste indicador as empresas } \\
\text { informam seus treinamentos de } \\
\text { formas diferentes e em alguns } \\
\text { casos incompleta. }\end{array}$ \\
\hline $\begin{array}{c}\text { Relacionam } \\
\text { ento }\end{array}$ & $\begin{array}{l}\text { A empresa informa o número } \\
\text { total de atendimentos } \\
\text { realizados e a porcentagem de } \\
\text { satisfação dos clientes. }\end{array}$ & $\begin{array}{l}\text { A empresa não informa } \\
\text { sobre os atendimentos ao } \\
\text { cliente. }\end{array}$ & $\begin{array}{l}\text { Neste indicador apenas a } \\
\text { empresa CSN informa seus } \\
\text { atendimentos e relacionamento } \\
\text { com o cliente. }\end{array}$ \\
\hline Acidentes & 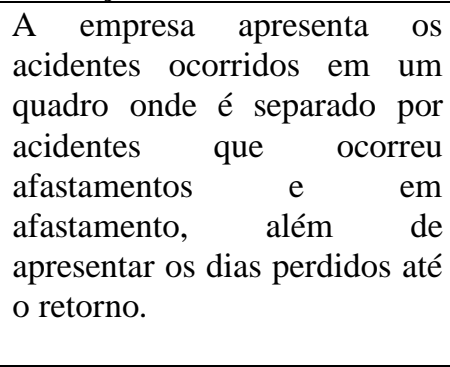 & $\begin{array}{l}\text { A empresa apresenta os } \\
\text { acidentes em um gráfico, } \\
\text { onde informa a gravidade e } \\
\text { os casos ocorridos. Há um } \\
\text { quadro onde informa } \\
\text { acidentes de trabalhadores } \\
\text { que não são funcionários, } \\
\text { mas é controlado pela } \\
\text { organização. }\end{array}$ & $\begin{array}{l}\text { Neste indicador as empresas } \\
\text { informam os acidentes ocorridos } \\
\text { e o grau de gravidade, mas não } \\
\text { há um padrão. }\end{array}$ \\
\hline
\end{tabular}

Fonte: Elaborado pelos autores. 


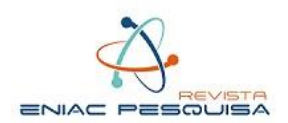

Na Tabela 5, novamente, é possível verificar que a falta de padronização dificulta a busca pelas informações, pois enquanto uma empresa apresenta dados detalhados e segmentados, a outra empresa não tem uma devida organização e não apresenta todas as informações.

\section{Tabela 6}

Indicadores relacionados ao capital natural

\begin{tabular}{|c|c|c|c|}
\hline Indicadores & $\begin{array}{c}\text { CSN - Cia Siderúrgica } \\
\text { Nacional }\end{array}$ & Gerdau & Comentário \\
\hline $\begin{array}{l}\text { Gastos com meio } \\
\text { ambiente }\end{array}$ & $\begin{array}{l}\text { A empresa apresenta as } \\
\text { informações por meio de } \\
\text { texto. }\end{array}$ & $\begin{array}{l}\text { A empresa não informa } \\
\text { os gastos com meio } \\
\text { ambiente. }\end{array}$ & $\begin{array}{l}\text { Neste indicador a falta de } \\
\text { padronização do relato } \\
\text { dificulta a comparação } \\
\text { das informações, devido } \\
\text { a Gerdau não informar } \\
\text { sobre os gastos com meio } \\
\text { ambiente. }\end{array}$ \\
\hline Reuso de água & $\begin{array}{l}\text { A empresa informa a } \\
\text { porcentagem de reuso e } \\
\text { reutilização de água em } \\
\text { suas unidades por meio } \\
\text { de texto. }\end{array}$ & $\begin{array}{l}\text { A empresa informa a } \\
\text { porcentagem de reuso e } \\
\text { recirculação de água por } \\
\text { meio de texto de forma } \\
\text { geral. }\end{array}$ & $\begin{array}{l}\text { Neste indicador as } \\
\text { empresas informam as } \\
\text { porcentagens de reuso de } \\
\text { água, mas a CSN } \\
\text { especifica a porcentagem } \\
\text { em cada unidade. }\end{array}$ \\
\hline Insumos reciclados & $\begin{array}{l}\text { A empresa apresenta as } \\
\text { informações sobre } \\
\text { resíduos reciclados e } \\
\text { reutilizados em forma de } \\
\text { texto e quadro, separados } \\
\text { em resíduos perigosos e } \\
\text { não perigosos. }\end{array}$ & $\begin{array}{l}\text { A empresa apresenta as } \\
\text { informações sobre } \\
\text { resíduos reciclados e } \\
\text { reutilizados em forma de } \\
\text { texto e quadro, separados } \\
\text { em resíduos perigosos e } \\
\text { não perigosos. }\end{array}$ & $\begin{array}{l}\text { Neste indicador ambas as } \\
\text { empresas informam seus } \\
\text { dados com textos e } \\
\text { quadros. }\end{array}$ \\
\hline Consumo de energia & $\begin{array}{l}\text { A empresa apresenta as } \\
\text { informações de consumo } \\
\text { de energia em forma de } \\
\text { texto e em um quadro, há } \\
\text { a separação por unidade. }\end{array}$ & $\begin{array}{l}\text { A empresa apresenta em } \\
\text { forma de texto e em um } \\
\text { gráfico o consumo total } \\
\text { de energia da companhia. }\end{array}$ & $\begin{array}{l}\text { Neste indicador fica } \\
\text { evidente a diferença com } \\
\text { que as empresas } \\
\text { apresentam seus dados. }\end{array}$ \\
\hline $\begin{array}{l}\text { Captação de água } \\
\text { (megalitros) }\end{array}$ & $\begin{array}{l}\text { A empresa informa por } \\
\text { meio de gráfico e quadro } \\
\text { a captação de água } \\
\text { realizada. }\end{array}$ & $\begin{array}{l}\text { A empresa informa a } \\
\text { captação de água em } \\
\text { forma de texto. }\end{array}$ & $\begin{array}{l}\text { Neste indicador é } \\
\text { possível verificar a } \\
\text { diferença entre as duas } \\
\text { apresentações, onde uma } \\
\text { empresa apresenta seus } \\
\text { dados de forma clara e a } \\
\text { outra empresa apresenta } \\
\text { de forma resumida. }\end{array}$ \\
\hline $\begin{array}{l}\text { Emissões de gases de } \\
\text { efeito estufa (toneladas) }\end{array}$ & $\begin{array}{l}\text { A empresa informa por } \\
\text { meio de texto e quadro a } \\
\text { emissão dos gases e } \\
\text { detalha cada gás. }\end{array}$ & $\begin{array}{l}\text { A empresa informa por } \\
\text { meio de texto e gráfico a } \\
\text { emissão dos gases. }\end{array}$ & $\begin{array}{l}\text { Neste indicador há uma } \\
\text { diferença na apresentação } \\
\text { dos gases, pois há } \\
\text { informações detalhadas } \\
\text { sobre cada gás na CSN e } \\
\text { a Gerdau apresenta de } \\
\text { forma geral os gases } \\
\text { emitidos. }\end{array}$ \\
\hline
\end{tabular}

Fonte: Elaborado pelos autores. 
Na Tabela 6, há certo nível de dificuldade na localização das informações no relato da Gerdau, pois as informações são passadas de forma resumida em apenas uma frase. O relato da CSN é mais completo e específico em seus indicadores. A falta de padronização dos relatos não colabora com a apresentação dos dados da pesquisa.

\section{Tabela 7}

Indicadores relacionados ao capital social e de relacionamento

\begin{tabular}{l|l|l|l}
\hline \multicolumn{1}{c|}{ Indicadores } & \multicolumn{1}{|c|}{$\begin{array}{c}\text { CSN Cia Siderúrgica } \\
\text { Nacional }\end{array}$} & \multicolumn{1}{c}{ Gerdau } & \multicolumn{1}{c}{ Comentário } \\
\hline $\begin{array}{l}\text { Proporção de } \\
\text { gastos } \\
\text { fornecedores }\end{array}$ & $\begin{array}{l}\text { A empresa apresenta a a empresa não } \\
\text { porcentagem de gastos } \\
\text { com fornecedores em um } \\
\text { quadro, onde é separado } \\
\text { cada segmento. }\end{array}$ & $\begin{array}{l}\text { A } \\
\text { informa os gastos } \\
\text { com fornecedores. }\end{array}$ & $\begin{array}{l}\text { Neste indicador apenas a empresa } \\
\text { apresenta seus gastos com } \\
\text { fornecedores. }\end{array}$ \\
\hline Projetos sociais & $\begin{array}{l}\text { A empresa apresenta em } \\
\text { forma de texto os projetos } \\
\text { realizados e a quantidade } \\
\text { de colaboradores. }\end{array}$ & $\begin{array}{l}\text { A empresa apresenta } \\
\text { em forma de texto os } \\
\text { projetos que são } \\
\text { realizados. }\end{array}$ & $\begin{array}{l}\text { Neste indicador as empresas } \\
\text { apresentam as informaçóes de forma } \\
\text { similar, pois ambas detalham seus } \\
\text { projetos e impactos na vida das } \\
\text { pessoas que participam dos projetos. }\end{array}$ \\
\hline
\end{tabular}

Fonte: Elaborado pelos autores.

Os indicadores de capital social e relacionamento são apresentados na Tabela 7, sendo possível analisar que a empresa Gerdau não apresenta informações sobre seus fornecedores, mas no caso dos projetos sociais, ambas as empresas detalham seus projetos e impactos. Vale ressaltar que o relato da empresa Gerdau não separa as informações por capitais, logo há a necessidade de busca das informações no relato para que seja possível fazer a análise.

\section{CONSIDERAÇÕES FINAIS}

A análise do relato integrado das empresas CSN - Companhia Siderúrgica Nacional e Gerdau evidencia a necessidade da padronização mínima deste tipo de relatório.

Enquanto a CSN tende a deixar as informações separadas por tópico (ou tipo de capital), a Gerdau apresenta as informações em blocos de textos únicos, onde o leitor consegue identificar os capitais apresentados através de um estudo minucioso desse relato.

A CSN apresenta maior nível de detalhamento quanto aos dados de sua produção, separando pelos diversos segmentos de produção de aço da companhia, enquanto a Gerdau opta por apresentar apenas os dados de suas principais linhas. Já em termos de Capital Financeiro, a Gerdau apresenta maior nível de detalhamento das informações, enquanto a CSN omite dados como o fluxo de caixa livre e o lucro líquido. 


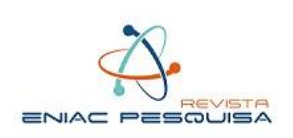

Apesar de não separar os dados de maneira segmentada, a Gerdau traz maior riqueza de detalhes quanto aos dados de Capital Humano, não só apresentando o total de colaboradores, mas apresentando o quão diverso é o time. Ambas as empresas apresentam em seu relato os esforços para a diversidade, embora apenas a Gerdau apresente como se reflete em seu quadro de colaboradores.

No que tange o Capital Natural, a CSN apresenta maior nível de detalhamento quanto à emissão de gases de efeito estufa, separando os dados por tipo de gás emitido, o que difere da Gerdau, que apresenta a informação de forma mais generalista. O mesmo ocorre com os dados de captação de água. A CSN também apresenta seu total em gastos com o meio ambiente, enquanto a Gerdau omite esta informação.

Outro fato relevante se refere a divulgação do relato integrado: enquanto a Gerdau divulga o relato anualmente, a CSN divulgou um único relato para os anos-base 2018 e 2019, o que denota a falta de padronização e dá liberdade para que as empresas divulguem ou não o relato ao fim do ano-base de referência. Isso também tende a mesclar informações de mais de um exercício, apesar do esforço em demonstrar as informações separadamente.

De uma forma geral, apesar da omissão de algumas informações, a CSN busca maior nível de detalhamento das informações em seu relato integrado, enquanto a Gerdau tende a apresentar uma versão mais resumida. Ambas as empresas pecam em determinados pontos pela falta de padronização, que se mostra urgente para uma melhor análise comparativa das empresas do segmento.

A pesquisa foi realizada apenas com duas empresas do setor, visto que nem todas apresentam o relato, o que dificulta uma análise mais completa do segmentado apresentado.

Foi possível concluir que a padronização dos relatos facilitaria a busca por informações e colaboraria com a própria comparabilidade interna e externa da empresa, além de auxiliar na tomada de decisões e de informar de forma clara e objetiva suas atitudes e processos para com a sociedade.

\section{REFERÊNCIAS}

Agenda 21. UNCED (1992) - Conferência das Nações Unidas sobre o Meio Ambiente e Desenvolvimento 1992, versão em português, Ministério do meio ambiente - MMA. Disponível em: <https://www.mma.gov.br/responsabilidade-socioambiental/agenda21/agenda-21-global/>. Acesso em: 22 out. 2020.

Alzate-Ibañez, Angelica Maria; Ríos, John Fredy Ramírez; Montoya, Laura Maria Bedoya (2018). Modelo para implantação de um sistema integrado de gestão da qualidade e meio 
ambiente em uma empresa do Siderúrgica. Ciências Administrativas, n. 13, pág. 032. Disponível em: < https://revistas.unlp.edu.ar/CADM/article/view/3810>. Acesso em: 16 fev. 2021. DOI: https://doi.org/10.24215/23143738e032

Andrade, Marcelo Aureliano Monteiro de; Gosling, Marlusa; Xavier, Wescley Silva. (2010). Por trás do discurso socialmente responsável da siderurgia mineira. Produção [en linea]. 20 (3), 418-428 ISSN: 0103-6513. Disponível em: <https://www.redalyc.org/articulo.oa?id=396742040010>. Acesso em: 16 fev. 2021.

Balardim, Adriana Rodrigues (2017). Relato Integrado: uma validação das diretrizes do Global Reporting Initative nas empresas listadas no índice de sustentabilidade empresarial da Brasil, Bolsa e Balcão. Dissertação (Mestrado em Ciências Contábeis e Atuariais). Pontifícia Universidade Católica PUC/SP. Disponível em: <https://tede2.pucsp.br/handle/handle/20555> Acesso em: 10 nov. 2020.

Carvalho, Pedro Sérgio Landim De; Mesquita, Pedro Paulo Dias; Araújo, Elizio Damião Gonçalves de (2015). Sustentabilidade da siderurgia brasileira: eficiência energética, emissões e competitividade. BNDES Setorial, v. 41, p. 181-236. Disponível em: < https://web.bndes.gov.br/bib/jspui/handle/1408/4287> Acesso em: 08 fev. 2021.

Esponda, María Alejandra; Strada, Julia. (2019) Terceirização de mão de obra na siderurgia argentina: empresas de ex-trabalhadores em Acindar Villa Constitución e Siderar Ensenada. Íconos. Revista de Ciencias Sociales Núm 64. pp. 159-181, ISSN (on-line) 1390-1249. Disponivel em: <https://revistas.flacsoandes.edu.ec/iconos/article/view/3401>. Acesso em: 17 fev. 2021. DOI: 10.17141 / icons.64.2019.3401

Guttmann, Robert. (2016). A transformação do capital financeiro. Economia e Sociedade, Campinas, SP, v. 5, n. 2, p. 51-83. Disponível em: <https://periodicos.sbu.unicamp.br/ojs/index.php/ecos/article/view/8643180>. Acesso em: 11 nov. 2020.

IIRC, I. I. R. C. A estrutura internacional para Relato Integrado. integratedreporting.org, 2013. Disponível em: <https://integratedreporting.org/wp-content/uploads/2015/03/13-12-08THE-INTERNATIONAL-IR-FRAMEWORK-Portugese-final-1.pdf $>$. Acesso em: 11 set. 2020.

Instituto Aço Brasil. (2020). Folder Aço Brasil Sustentabilidade 2020. Disponível em: $<$ https://acobrasil.org.br/site/wp-content/uploads/2019/08/SUSTENTAB_digital_20201.pdf>. Acesso em: 06 out. 2020.

Matos, Antônio Teixeira. (2010). Poluição Ambiental: Impactos no Meio Físico. Brasil. Disponível em: <https://books.google.com.br/books?hl=pt-BR\&lr=\&id=2FEEEAAAQBAJ\&oi=fnd\&>. Acesso em: 10 nov. 2020.

Nagano, Renan Toshi; Kassai, José Roberto; Kussaba, Cristiane Tiemi; Carvalho, Luiz Nelson Guedes. (2013). A Evolução Dos Relatórios De Sustentabilidade E A Necessidade Da Obrigatoriedade De Sua Asseguração Por Terceiros. Disponível em: < http://repositorio.uninove.br/xmlui/handle/123456789/574>. Acesso em: 17 fev. 2021. 
O'connor, Martin. (1999). Natural capital. Policy Research Brief Series, n. 3, Cambridge Research for the Environment. Disponível em: 〈https://clivespash.org/eve/PRB3-edu.pdf>. Acesso em: 14 out. 2020.

ONU. Sobre o nosso trabalho para alcançar os Objetivos de Desenvolvimento Sustentável no Basil. 2020. Disponível em: 〈https://brasil.un.org/pt-br/sdgs〉. Acesso em: 22 out. 2020.

Peixoto, Nathália Oliveira. Martins, Vidigal Fernandes. (2015). Relato integrado e a convergência com relatórios de sustentabilidade: Um estudo em empresas brasileiras. Revista de Auditoria Governança e Contabilidade v. 3, n. 7. Disponível em: < http://fucamp.edu.br/editora/index.php/ragc/article/view/599>. Acesso em: 17 fev. 2021.

Silva, L. R. da. (2019). Impactos socioambientais na Amazônia Oriental: um olhar a partir da atividade siderúrgica na comunidade Piquiá de Baixo - Açailândia (MA). Geopauta, [S. l.], v. 3, n. 4, p. 5-18. DOI: 10.22481/rg.v3i4.5781. Disponível em: <https://periodicos2.uesb.br/index.php/geo/article/view/5781>. Acesso em: 17 fev. 2021. DOI: https://doi.org/10.22481/rg.v3i4.5781

Silva, R. C.; Santos, F. de A.; Santos, N. M. N. F. (2019). A Atuação do Relato Integrado nas Empresas Brasileiras: Um estudo comparativo sobre a forma de divulgação do RI entre os dois maiores bancos privados nacionais. Revista Metropolitana de Sustentabilidade. Volume 9, Número 2 (Maio/Ago.) Disponível <http://revistaseletronicas.fmu.br/index.php/rms/article/view/2065/pdf>. Acesso em: 20 out. 2020.

Vaz, Caroline Rodrigues. Rocha; Paula Regina Zarelli; Werutsky, Viviane D' barsoles gonçalves. Selig, Paulo Mauricio. Morales, Aran Bey Tcholakian. (2014). Modelos De Mensuração do Capital Intelectual Para Tomada De Decisão E Variáveis De Desempenho. Iberoamerican Journal of Industrial Engineering, Florianópolis, SC, Brasil, v. 6, n. 11, p. 245 260, 2014. Disponível em: 〈http://incubadora.periodicos.ufsc.br/index.php/IJIE/article/view/3060>. Acesso em: 11 nov. 2020. DOI: 10.13084/2175-8018/ijie.v6n11p245-260 